\title{
Seroepidemiology of infection with Herpes Simplex Virus type 2 (HSV2) among asymptomatic students attending Islamic Azad University of Kazeroun, southwest of Iran
}

\author{
Daryoush Tayyebi ${ }^{1 *}$, Mojgan Tabatabaee ${ }^{1}$, Marjan Rahsaz ${ }^{2}$ \\ From $16^{\text {th }}$ International Symposium on HIV and Emerging Infectious Diseases \\ Marseille, France. 24-26 March 2010
}

\section{Background}

Herpes simplex virus (HSV) infections are among the most common infectious diseases in humans. The prevalence of herpes simplex viruse type 2 (HSV-2) varies widely across the world. Herpes simplex virus type 2 (HSV-2) is the cause of most genital herpes and is almost always sexually transmitted.

Most HSV-2 infections are consequently expected to occur after the onset of sexual activity. Genital herpes is a cause of morbidity and increases the risk of HIV acquisition, due to disruption of mucosal membranes.

Data on prevalence of herpes simplex virus type 2 (HSV-2) infections are limited in Asia.

Our study focuses on seroepidemiology of HSV-2 infection in Islamic Azad University of Kazeroun asymptomatic healthy students.

\section{Methods}

In our descriptive study, the study group comprised 360 students with the average age of 22.2. At the beginning, demographic data were recorded by using a questionnaire. For serological studies $5 \mathrm{ml}$ of blood sample was collected and the serum was isolated by centrifugation. Enzyme linked immunosorbent assay (ELISA) was used for determination of immunoglobulin G (IgG) antibody titer to the HSV-2. Finally the results were analyzed by statistical methods.

\section{Results}

Overall, HSV-2-IgG antibody was positive in 84 persons $(23.3 \%)$ out of 360 subjects and they had a previous infection.

We can find a significant difference in prevalence between men and women but didn't find any significant relationship between students with different field of study and their residence $(\mathrm{p}>0.05)$.

\section{Discussion}

The overall incidence of HSV-2 infection in this study was $23.3 \%$.

Certainly information on age- and gender-specific prevalence of HSV-2 infection is crucial to guide herpes control strategies and prevention of HSV-2 infection should target individuals before they become sexually active.

\section{Author details}

${ }^{1}$ Islamic Azad University-Kazeroun Branch, Kazeroun, Iran, Islamic Republic Of. ${ }^{2}$ Transplantation Research Center, Shiraz, Iran, Islamic Republic Of

Published: 11 May 2010

doi:10.1186/1742-4690-7-S1-P88

Cite this article as: Tayyebi et al:: Seroepidemiology of infection with Herpes Simplex Virus type 2 (HSV2) among asymptomatic students attending Islamic Azad University of Kazeroun, southwest of Iran. Retrovirology 2010 7(Suppl 1):P88.

* Correspondence: dtayyebi@yahoo.com

${ }^{1}$ Islamic Azad University-Kazeroun Branch, Kazeroun, Iran, Islamic Republic Of 